\title{
Cracking in desiccating soils
}

\author{
Alberto Ledesma ${ }^{1 a}$ \\ ${ }^{1}$ Universitat Politècnica de Catalunya - UPC-BarcelonaTech, Barcelona, Spain
}

\begin{abstract}
Soil shrinkage is produced typically under desiccating conditions. Eventually shrinkage may generate cracks in the soil mass, a phenomenon that is being studied by several researchers, because its prediction is far from being a routine in Soil Mechanics. Within this context, Unsaturated Soil Mechanics provides a promising framework to understand the mechanisms involved. In addition to that, physical modelling of desiccating soils constitutes a good tool to explore the nature of this problem. In this paper, a description of the processes involved in desiccating soils is presented first. There is a debate in the Soil Mechanics community about the conditions leading to the initiation of a crack and some of those issues are addressed in the paper. Then, two physical modelling strategies to study desiccating soils are briefly described: a laboratory environmental chamber and a field controlled test. The chamber was able to reproduce drying and wetting cycles by controlling the relative humidity of the environment that affected the moisture conditions of a soil tray. Temperature was a controlled variable as well. The second experiment refers to a field test, exposing a large soil tray to standard environmental actions in the field, that is, cycles of temperature, solar radiation, relative humidity, rain, wind, etc. In this case, actions cannot be controlled, but they can be measured. An effort was devoted to measure internal variables in the soil mass, mainly temperature, suction and water content. Additionally changes of weight were recorded as well. In essence the paper gives a general overview of the mechanisms involved in soil cracking and the physical modelling procedures employed to analyse this phenomenon in practice.
\end{abstract}

\section{Introduction}

Shrinkage of soils due to desiccation is a common process in natural dry environments. Eventually, that shrinkage may induce cracking and soil becomes degraded loosing strength, bearing capacity, and increasing permeability. In that context, volume changes (shrinkage) and cracking are phenomena related to the interaction between soil and atmosphere ([1]-[4]). Cracking on the ground surface due to desiccation has been reported quite often, including some giant cracks described by Harris [5]. Recently, cracks observed on Mars surface have been attributed to desiccation processes as well [6].

The analysis of cracking in desiccating soils is a topic with increasing interest in the geotechnical community. Preliminary publications are quite isolated (i.e. [7]), but the publications have increased significantly after the 90's ([8], [9]). Physical modelling was considered by many researchers a convenient tool to understand the processes involved in soil cracking due to desiccation. Laboratory experiments included not only the observation of drying samples, but also the development of environmental controlled chambers to observe the pattern of cracking ([10]-[13]). In recent years, numerical simulations of soil cracking have been presented using different strategies involving finite elements with interfaces or discrete elements ([14]-[16]). The topic, initially covered by soil scientists, is becoming more popular among geotechnical experts and was included in the list of themes in the 2013 Geo-Congress organized by ASCE in San Diego [17].

This paper presents first an analysis of the problem by using an Unsaturated Soil Mechanics approach. This is particularly useful despite the fact that cracks initiate when soil is still saturated. However water pressures in the soil are at that moment negative and therefore suction must be taken into account as most of the soil properties are suction dependent. Some basic laboratory experiments are also described. The second part of the paper includes the description of two physical models that have been used in this case: an environmental chamber, controlling relative humidity and temperature over a monitored soil tray, and a field experiment where a large soil container is subjected to atmospheric actions, i.e., solar radiation, temperature, wind, relative humidity changes, rain, etc. Both tests are important to understand the mechanisms involved in the initiation and propagation of the cracks. The field test has been recently set up and it is described in detail in another paper in this Conference [18]. However, here it is presented as a complement to the laboratory environmental chamber.

\footnotetext{
a Corresponding author: alberto.ledesma@upc.edu
} 
Both experiments are compared and the advantages and disadvantages of each test are briefly discussed.

\section{Soil drying}

When a soil sample is continuously dried in the laboratory, a reduction of volume (shrinkage) is observed up to a point after which the total volume remains constant. The process is related to the evaporation of pore water and that explains the reduction of volume. A typical shrinkage curve is depicted in figure 1 , representing total volume vs water content, starting at point A and drying the sample to points B and finally D.

The Atterberg limits have been represented in the horizontal line, from liquid limit $\left(\mathrm{w}_{\mathrm{L}}\right)$ to plastic limit $\left(\mathrm{w}_{\mathrm{P}}\right)$ and shrinkage limit $\left(\mathrm{w}_{\mathrm{S}}\right)$. Line $\mathrm{C}-\mathrm{D}$ represents the path where total volume is constant and it is assumed that air enters the soil pores. A classical convention in Soil Mechanics considers that soil is unsaturated when water content is below shrinkage limit [19]. Also, between plastic and shrinkage limits, soil is assumed to be saturated, but with water in tension. That may not be precise in some cases, as liquid and plastic limits are defined in an empirical manner, but it is convenient in order to have a framework to understand this drying process. Real experiments provide curved paths, instead of straight lines A-B-C-D. In fact, gradient of line A-C is similar for most soils, as it depends on the specific weight of solid particles and water only. If soil is saturated, the total volume, $\mathrm{V}_{\mathrm{T}}$, is obtained by adding the volume of solid, $\mathrm{V}_{\mathrm{S}}$, and water, $\mathrm{V}_{\mathrm{w}}$ :

$$
V_{T}=V_{W}+V_{S}=W_{S}\left[\frac{w}{\gamma_{w}}+\frac{1}{\gamma_{S}}\right]
$$

where $\mathrm{W}_{\mathrm{S}}$ is the weight of solid particles, $\mathrm{w}$ is the gravimetric water content, $\gamma_{\mathrm{w}}$ is the specific unit weight of water and $\gamma_{S}$ the specific unit weight of solid particles. Thus for a particular value of solid particles weight, gradient of line A-B is well defined, as shown in figure 2 ([20]). That gradient becomes 1 (that is, $45^{\circ}$ ), if the volume per $100 \mathrm{~g}$ of dry soil is represented in the vertical axis.

It is possible to extend equation (1) for unsaturated conditions and straight lines are obtained depending on the degree of saturation. In that figure, gradients corresponding to unsaturated conditions $(\mathrm{S}<100 \%$, being $\mathrm{S}$ degree of saturation) are depicted as well. This is an indication that curved paths after B suggest a desaturation of the soil sample, so deviation from line A-B indicates air entry.

Although gradient of line A-B (figures 1 and 2) is similar for most soils, the volume change when drying a sample from the liquid limit to the plastic limit is very much soil dependent. High Plasticity Index (PI) values $\left(\mathrm{PI}=\mathrm{w}_{\mathrm{L}}-\mathrm{w}_{\mathrm{P}}\right.$ where $\mathrm{w}_{\mathrm{L}}$ is the liquid limit and $\mathrm{w}_{\mathrm{P}}$ is the plastic limit) results in a large volume change when drying and therefore, a tendency to crack because of inhomogeneous deformations. This is consistent with the observations: desiccation cracks are more frequent on high plasticity clayey deposits.

\section{Crack initiation}

Desiccating a sample in the laboratory as indicated in figure 1 may not produce any crack. If the strain field is homogeneous, a global shrinkage without cracks will develop. However, a crack should be expected to appear when the strain field is not homogeneous. Cracking seems to depend on boundary conditions. Nevertheless, cracks may initiate where there is a defect in the soil mass. There are evidences of both situations reported in the literature. In fact, cracks are consequence of heterogeneity either in the strain field or in the soil mass.

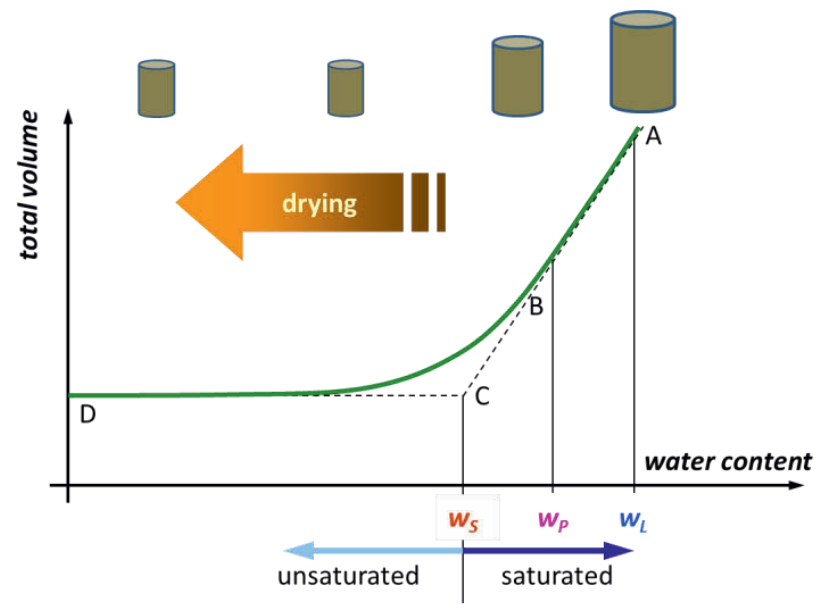

Figure 1. Typical soil shrinkage curve: total volume vs water content.

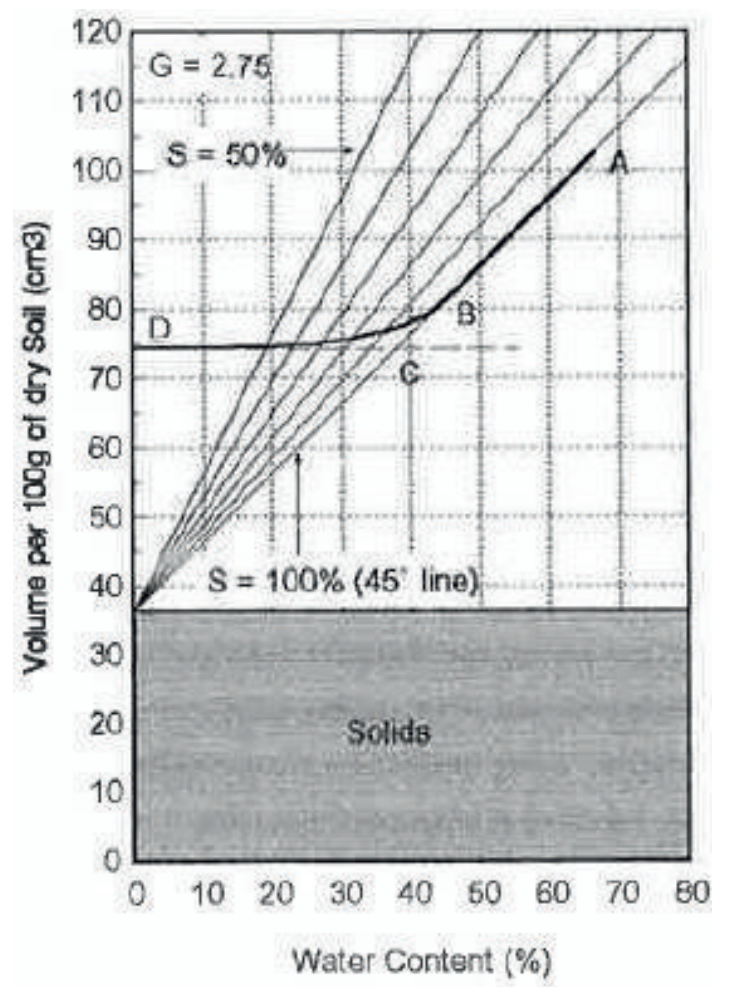

Figure 2. Quantitative shrinkage curve for a soil (from Marinho, [20]) 
On the one hand, Shin and Santamarina ([21]) suggested that cracks initiate at the bottom of the defects. They performed experiments by desiccating soil samples (slurry montmorillonite) in plastic containers and identified the initiation of cracks with heterogeneities or defects in the soil mass. Defects are random and difficult to predict in practice. Because of that, when attempting to simulate this process numerically, some researchers have assigned random material properties to each soil element [22]. In this manner, cracks developed first in those elements where tensile strength was lower.

On the other hand, Ávila et al ([23]) showed that in some cases cracks can be predicted as they depend directly on the stress and strain fields. They carried out desiccating experiments with Bogotá clay, $\mathrm{CH}$ (Soil Universal classification), $\mathrm{w}_{\mathrm{L}}=62 \%, \mathrm{w}_{\mathrm{P}}=30 \%$ and being the main minerals Kaolinite (55\%), Smectite $(17 \%)$ and Illite (15\%). Several soil "I-shaped" trays were prepared by using that clay desiccated under laboratory conditions. Figure 3 presents pictures of 3 experiments starting at different water contents and after different desiccation times. Note that cracks were produced always in the same areas, that is, location of cracks could be reasonably predicted due to the restraint of boundaries in the shrinkage of the samples.

Therefore, the experiments show that cracks are related to heterogeneities either in the soil properties or in the stresses. If the material is homogeneous, then stress/strain field becomes crucial and boundary conditions may play a fundamental role. However, if there is any heterogeneity in the soil mass, defects will be the ideal place for crack initiation. When performing experiments in the laboratory it is important to prepare a homogeneous soil mass (starting from a liquid consistency facilitates that task), in order to minimise the defects within the soil mass.

In a laboratory environment, the initiation of the cracks seems to be controlled by hydro-mechanical conditions, assuming that temperature is constant. Experiments indicate that cracks initiate when the soil is still under saturated conditions, although suction may be developed. That situation corresponds to the zone in the water retention curve close to $100 \%$ of saturation, as shown in Figure 4, corresponding to the clay used in the experiments reported in [23]. Therefore, suction plays a role close to the crack initiation, and Unsaturated Soil Mechanics seems to be a convenient approach to analyse this particular problem.

Most recent works dealing with cracking in drying soils consider the tensile strength as failure criterion to define whether a crack initiates or not in a particular point of the soil mass ([10], [15], [16], [22]). This failure criterion, however, has been criticised as too simplistic ([21]). There is some evidence that other mechanisms are involved in the initiation of the crack. In fact when suction appears, soil is compressed in all directions and therefore, when tensile stresses develop in one direction, some compression due to suction is acting in other directions and a shear failure component should be expected [23]. That makes the stress state three dimensional and complicates the analysis.

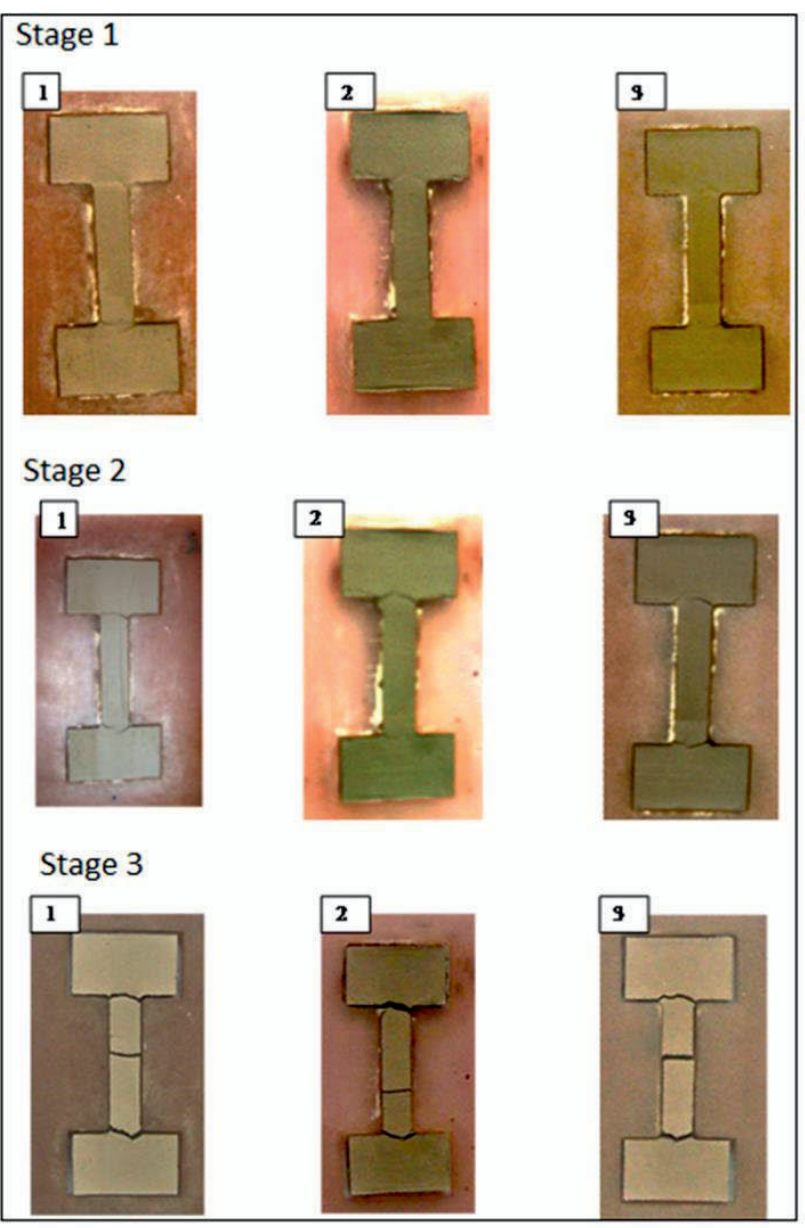

Figure 3. Desiccation of 3 "I-shaped" soil trays starting from different initial water content conditions. First row: pictures after 4 hours, second row: after 4 hours $35 \mathrm{~min}$, third row: after 22 hours. [23]

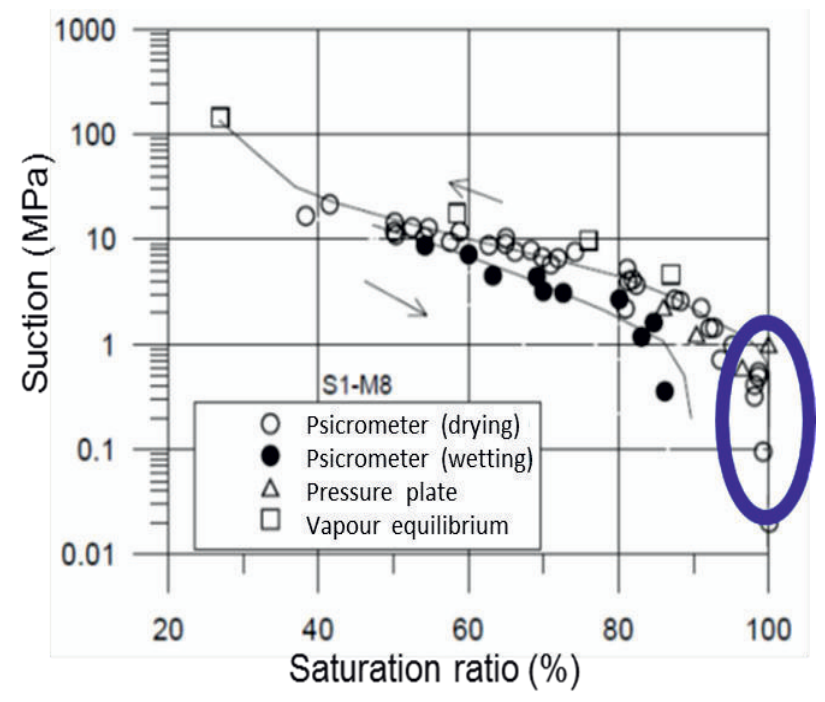

Figure 4. Soil water characteristic curve for the Bogotá clay used in previous experiments. Curves measured in drying and wetting paths using different techniques [23]. The zone marked with a blue thick ellipse corresponds to the conditions where cracking initiation may be expected: close to saturation and low suction values. 
Tensile strength criterion can be used for the sake of simplicity if suction effects are taken into account to some extent. Indeed tensile strength depends on water content and therefore, on suction, as shown in Figure 5, from [23]. Increasing water content decreases tensile strength, approaching a very small value when reaching liquid consistency.

A hydro-mechanical (HM) analysis of the desiccation problem is feasible and can be carried out by considering the equilibrium equation, the solid mass balance equation and the water mass balance equation considering unsaturated conditions. Air balance equation is not required if air pressure is assumed to be constant in the soil mass. In addition to that, some further ingredients are required to simulate drying: generalised Darcy's law, unsaturated permeability depending on degree of saturation, water retention curve and tensile strength depending on suction. While the soil is a continuous medium, the conventional coupled HM formulations used for porous media may apply. Therefore, soil drying up to the crack initiation can be simulated numerically by using standard finite element codes solving HM equations in unsaturated conditions [10].

\section{Crack propagation}

Propagation of cracks can be simulated by extending the previous coupled HM formulations to take into account crack opening when tensile stress reaches the tensile strength. However, additional difficulties arise, as cracks may constitute a new boundary where evaporation can take place. Figure 6 presents the results of simulating the drying process of a soil tray by using an HM formulation [24]. Soil separates from the tray wall, so soil nodes are released when tensile stress reaches the tensile strength and the suction boundary condition is extended to the released nodes.

It seems appropriate to consider that propagation of cracks is a phenomenon involving release of energy and therefore, a fracture mechanics approach may be convenient to explain that behaviour. There are experimental evidences of that relationship between crack propagation and fracture mechanics including the confirmation of size effect laws ([25]). Linear Elastic Fracture Mechanics was initially used as theoretical framework, but soon, non-elastic theories were proposed, as the cohesive-crack method [26]. In this context, some attempts to measure fracture mechanics properties of soil samples have been reported [27]. However, still most of the works simulating numerically crack propagation in soils use a tensile strength criterion to check whether a crack propagates or not. From a numerical point of view, they use a technique based on initial joints between element faces, that is, a sort of Voronoi-based discretization technique, capable of representing discrete fracture networks ([15], [16]). Discrete element method is particularly appropriate for this type of problems [14]. Adapting the hydraulic problem (unsaturated flow) to the new cracked geometry constitutes a challenge in this case.

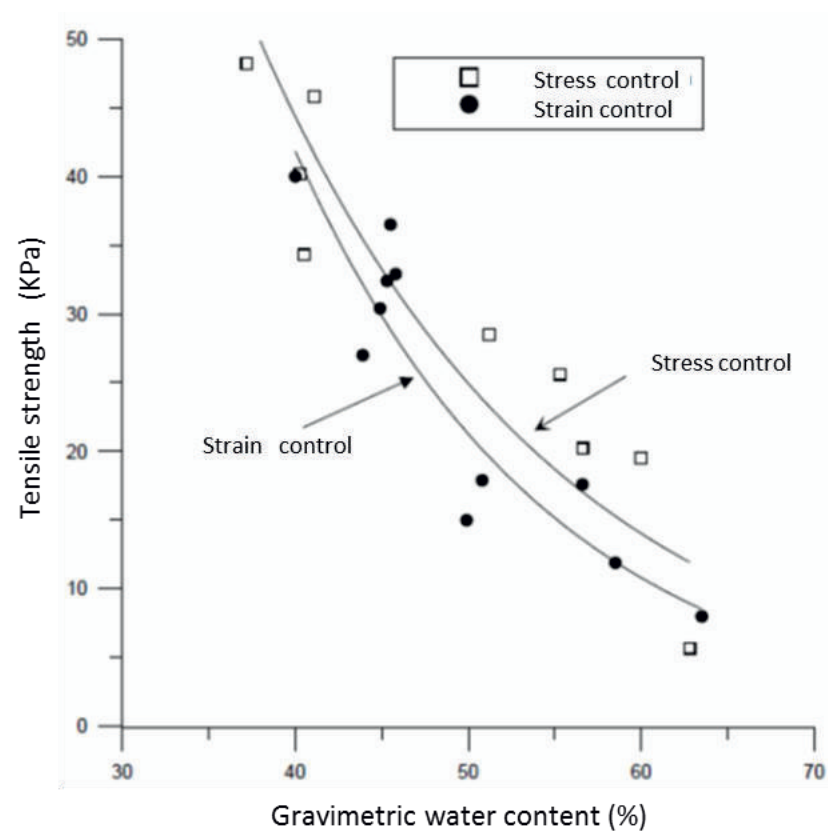

Figure 5. Tensile strength as a function of gravimetric water content for Bogotá clay, measured in stress controlled and strain controlled tests [23]

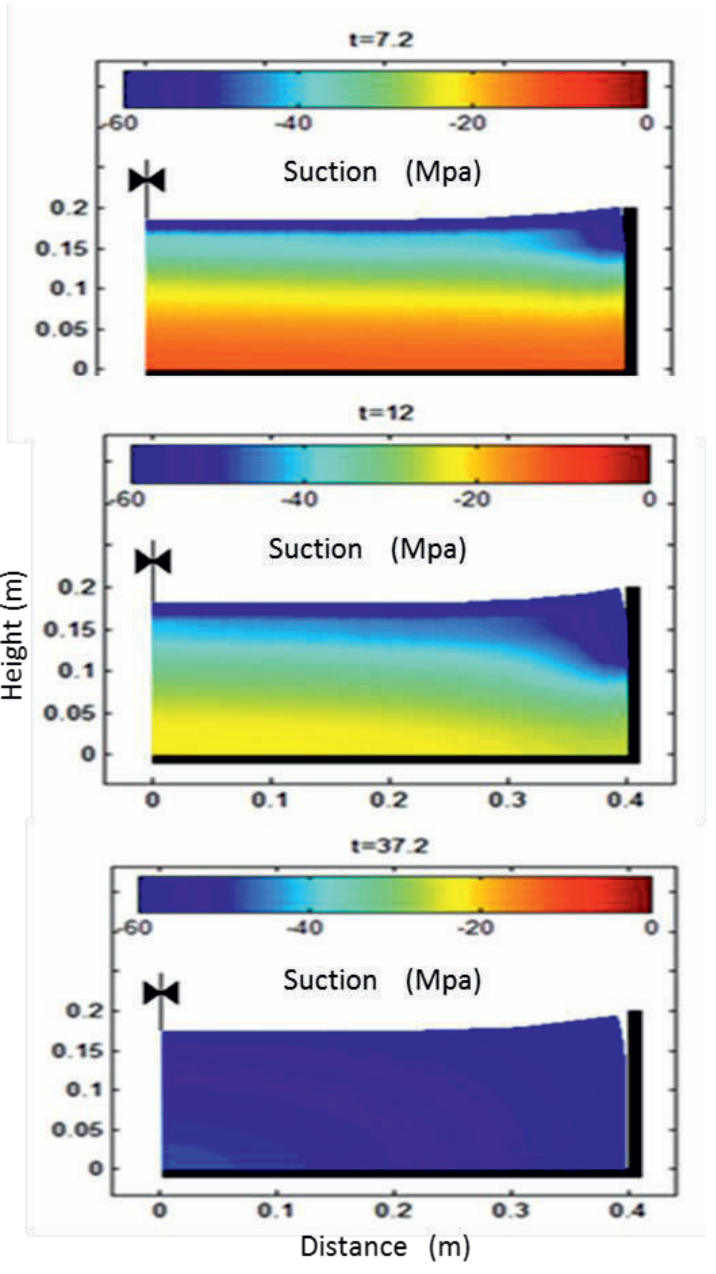

Figure 6. Numerical simulation of a desiccation test at different times (hours) developing a crack in the soil-wall contact ([24]). 


\section{Physical modelling: Laboratory tests}

Cracking patterns are very complex to predict in advance. Therefore, the use of physical models may be convenient to understand the processes involved in practical cases. In the laboratory, environmental chambers have been developed in the last decade to reproduce soil drying at an intermediate scale ([12], [29]). Figure 7 shows one of this chambers developed at UPC [28], where it is possible to control temperature and relative humidity inside the chamber, imposing dry conditions to a soil tray. Those trays are instrumented, so the time evolution of main variables is recorded, including weight of the tray and suction, water content and temperature at particular locations inside the soil sample.

Modern environmental chambers include a system to circulate dry or wet air so cycles of drying and wetting episodes can be imposed to the soil sample. This is to create conditions similar to what it is found in nature. Figure 8 shows two pictures of one experiment lasting for more than two months, where first a drying boundary condition is applied to the sample $(80 \mathrm{~cm}$ in diameter) and then a wetting is imposed (air relative humidity close to $100 \%$ ). It should be pointed out that wetting may close some small cracks due to the expansion when reducing suction, but what dominates is the formation of new cracks. This effect is related to the reduction of tensile strength when reducing suction, as suggested in Figure 5.

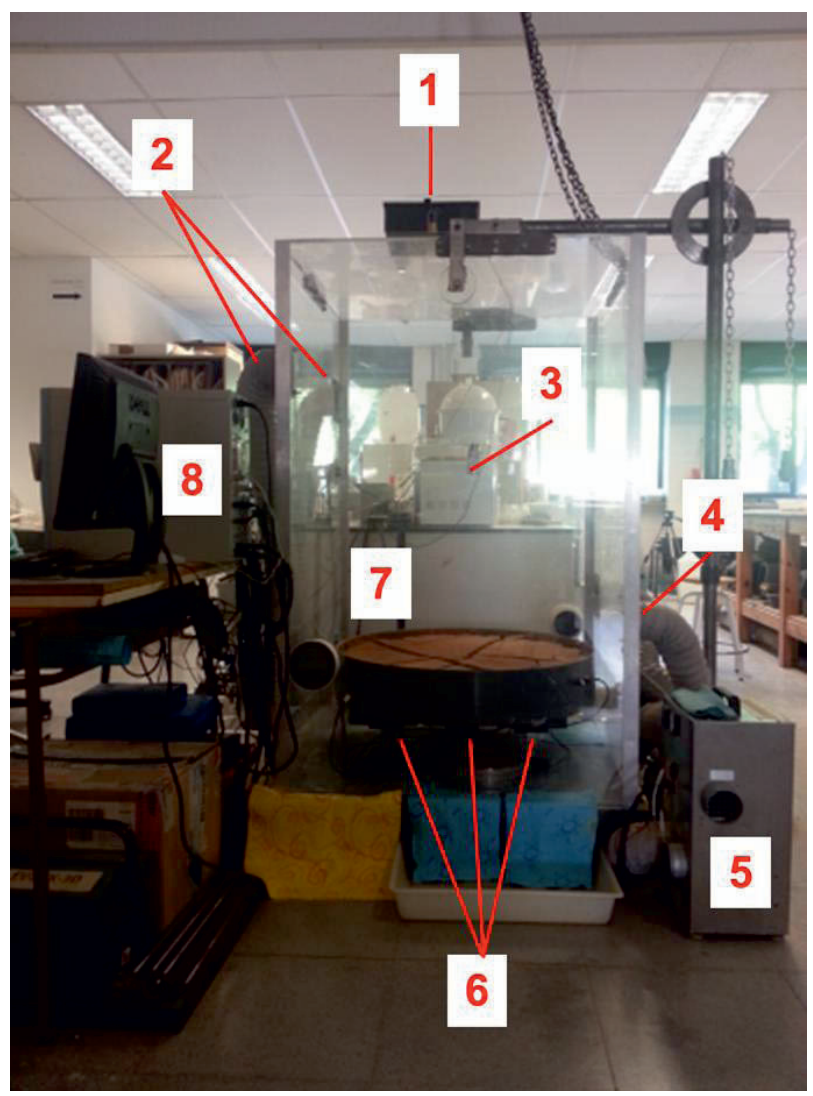

Figure 7. Environmental chamber to study soil desiccation. 1. Digital camera; 2. Dry/Wet air entry; 3. Thermometer; 4. Wet air exit; 5. Dehumidifier; 6. Load cells; 7. Soil specimen; 8 . Computer and data logger. ([12], [28]).
In some cases, the vertical cuts at each side of a surficial crack become unstable when wetting the soil. Then small wedges fall down to the crack due to the reduction in apparent cohesion and new cracks appear. This effect can be observed in the lower picture of Figure 8.

These types of experiments have been useful to understand some of the mechanisms involved in desiccating soils. The experience from the environmental chambers confirms that suction gradient between the soil and the air of the chamber is the main driving mechanism producing desiccation in this context. Temperature gradients can be also applied and may have influence on the evaporation of water from the soil. Drying processes are quite fast in general, whereas wetting the sample after drying seems to be more difficult. Indeed there is a hysteretic effect and to saturate the sample once it has been cracked requires imposing a $100 \%$ of relative humidity to the environment. This is due to the low permeability of the dry cells between cracks.

Finally, some experiments have shown that sometimes cracks do not start at the soil surface, but at the bottom of the specimen [30]. Differential drying between surface and bottom may lead to curling of the sample as well.
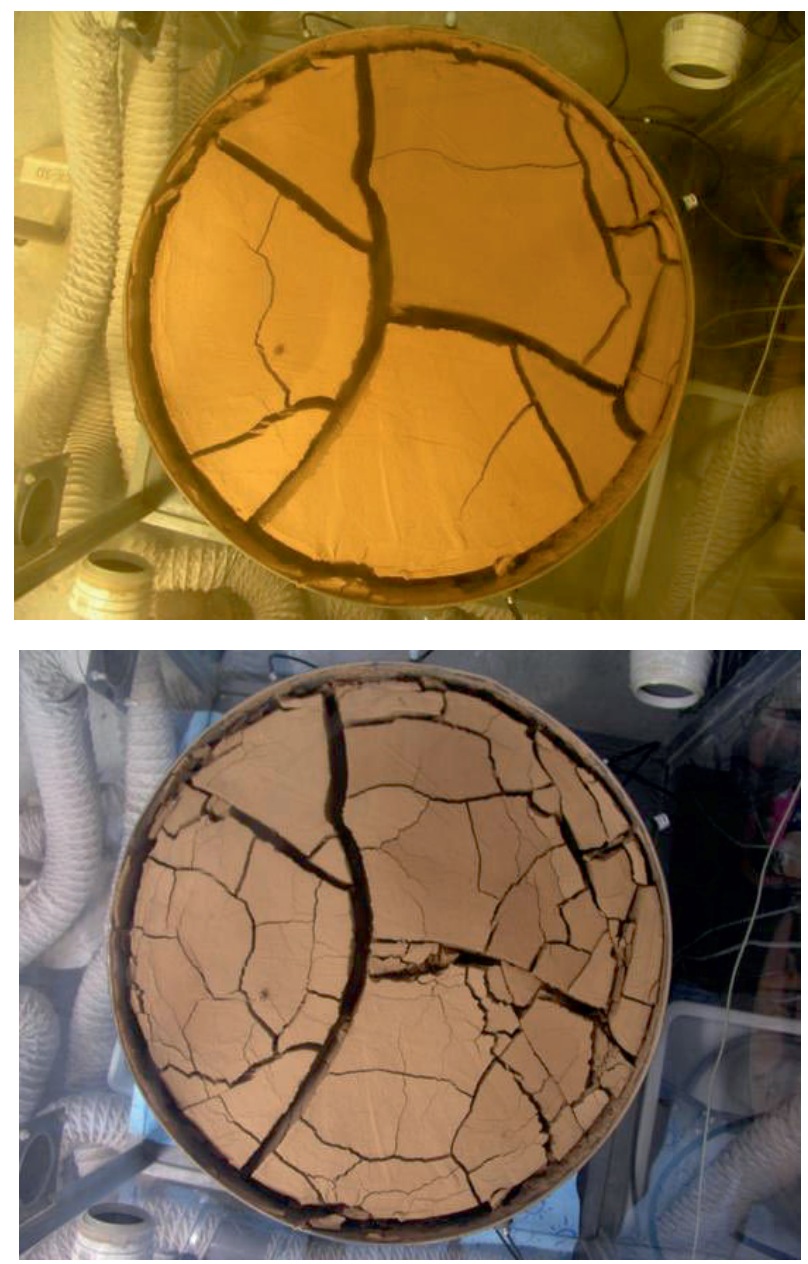

Figure 8. Pattern of cracks in a soil tray after a long period inside the environmental chamber. Above: After 1 month of continuous drying. Below: new cracks develop when wetting again after a drying period. [28]. 


\section{Physical modelling: Field tests}

In addition to environmental chambers, physical modelling may refer to field controlled experiments as well. This is a natural extension of the work carried out in the laboratory, with the aim of understanding the processes involved in actual desiccating conditions. It becomes then evident that other variables, not considered so far, are involved in the physics of the test, basically meteorological variables, as solar radiation and wind velocity. From the experience in environmental chambers, there is increasing evidence that close to the soil surface most of the variables exhibit important gradients. Therefore, an effort should be devoted to the measurement close to the soil surface. Note that sensors may constitute a preferential flow path and a particular onset of cracking. There is always a compromise between installation of sensors and maintaining the soil mass as homogeneous as possible.

Figure 9 shows a picture of a field test that has been recently set up at UPC on a site called Agrópolis, near Barcelona airport. Details of the deployment of the experiment are described in a companion paper in this Conference [18]. That Figure shows the external instrumentation installed with the objective of measuring as close to the surface as possible. Remote sensors have been installed as well: temperature infra-red sensor and a reflectometer sensor, trying to obtain information on temperature and water content in a remote manner. Meteorological variables are also provided by a weather station located nearby. The installation replicates a typical soil tray used in the laboratory, but using larger dimensions: $3 \mathrm{~m} \times 3 \mathrm{~m} \times 0.5 \mathrm{~m}$ depth. Load cells control continuously the weight loss due to drying or any eventual weight gain due to rain.

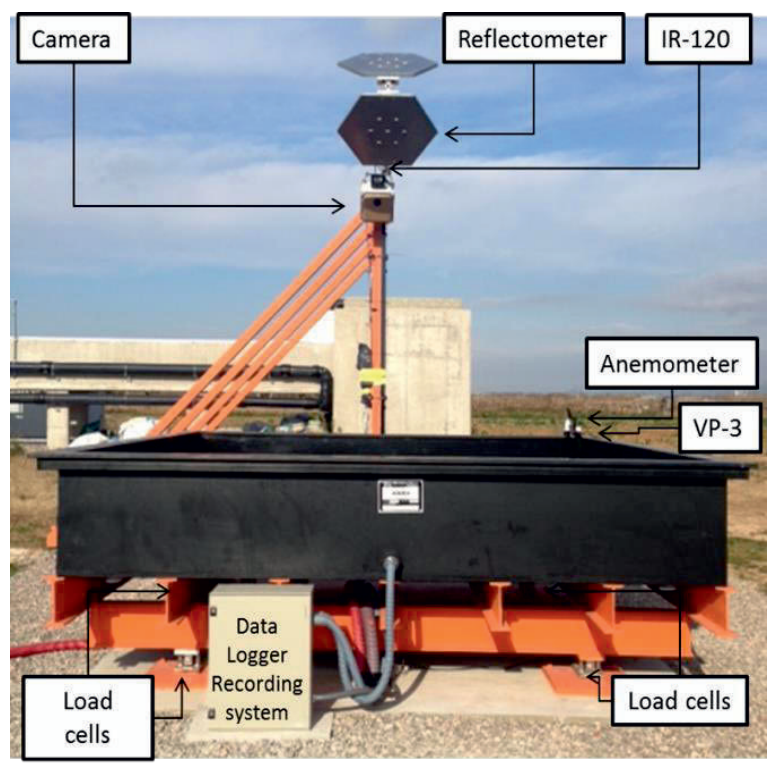

Figure 9. Overview of the field test and main components of the external instrumentation. IR-120 is an infra-red remote temperature sensor. VP-3 is a relative humidity, air temperature and vapour pressure sensors.
The test has been in operation from one year and it is being processed right now. Figure 10 presents a preliminary result concerning temperature values in a vertical line including soil and air above soil surface. It becomes evident that temperature profile is quite complex and that a gradient is developed around soil surface. An interpretation of this type of results is still an ongoing work. It could be stated that in the atmosphere, just above soil surface, there is a "limit layer" where the main gradients in terms of temperature and relative humidity develop. When water evaporates, a layer of wet air above soil surface remains there, unless wind takes away that moisture speeding the drying process. Therefore, wind velocity above soil surface becomes an important factor.

Another factor that seems crucial is solar radiation. In Mediterranean climate, heat flow due to solar radiation has an important influence on the temperature profile and therefore on the capacity to evaporate water. Note that radiation may enter the soil mass and thus it is not just a simple boundary condition on the soil surface. A numerical simulation of heat transport in the soil should take into account all the mechanisms involved, including radiation.

These two factors constitute the main difference between experiments performed in the laboratory and field experiments. Figure 11 presents the comparison between two of those experiments: a test in an environmental chamber was designed to reproduce the same weight loss - time curve measured in the field test shown in Figure 9. In the laboratory, almost a constant relative humidity of $30 \%$ was imposed in the environmental chamber, whereas in the field, relative humidity changed a lot in the range $20 \%-95 \%$, but with average values above $50 \%$. The lines in Figure 11 show the evolution of the water loss measured in terms of weight change divided by surface area, to compare dimensions of laboratory and field trays.

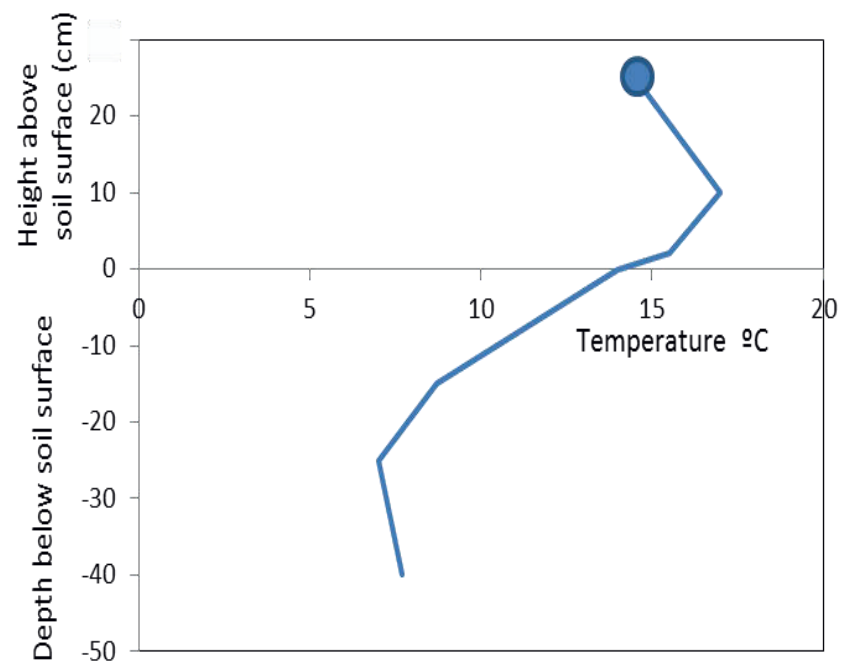

Figure 10. Temperature profile in the soil and above soil surface (maximum temperatures measured for a particular day). Dot corresponds to the temperature data from the Weather station. 


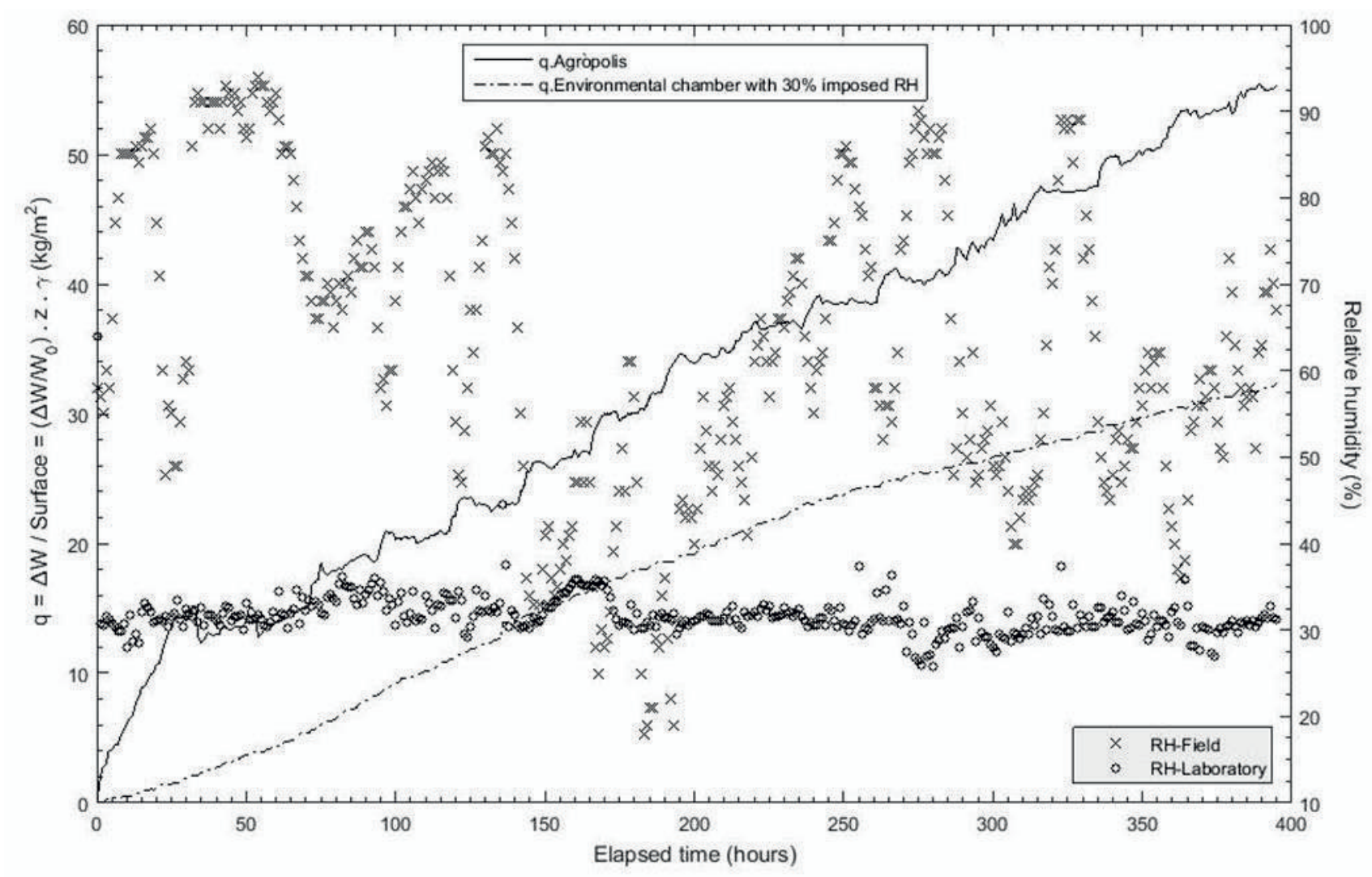

Figure 11. Comparison between laboratory environmental chamber and field test for a period of time. Evolution of relative humidity and loss of water measured as change of weight divided by exposed soil surface.

Analysis of Figure 11 indicates that comparing environmental chamber and field experiment is not straightforward and this is because some of the variables are different in both tests. It can be seen on that Figure that the loss of water per unit area is more important in the field, with relative humilities well above $50 \%$, than in the environmental chamber imposing an extreme $30 \%$ of constant relative humidity. The reason for that discrepancy is the contribution of heat transported by radiation and wind velocity that are not reproduced in an environmental chamber. Those effects should be taken into account in the future when developing numerical simulations of cracking in desiccating soils in nature.

\section{Conclusions}

The paper presents a general perspective of the shrinkage and cracking of desiccating soils describing briefly the mechanisms involved and the methods and techniques available to study this type of problems. The initiation of the crack seems to be controlled by the hydromechanical conditions of the soil mass and therefore, an Unsaturated Soil Mechanics approach seems to be a convenient framework. Most of the criteria for crack initiation and propagation are based on tensile strength and future works should improve that, taking into account the effect of suction compressing in other directions. Propagation of cracks seems to be controlled by Fracture Mechanics variables and there is still room for improvement, regarding the numerical simulation of this phenomenon, as the information on Fracture Mechanics properties of unsaturated soils is scarce.

Physical modelling of drying soils is always a valuable tool to understand the processes involved in a large scale experiment. However, environmental chambers are based typically on controlling relative humidity boundary condition, whereas in the field, a more complex boundary condition acts on the soil surface. When comparing laboratory environmental chambers with field experiments it becomes apparent that heat transported by radiation plays an important role at least in Mediterranean areas. Also wind velocity close to the soil surface is fundamental to characterize the boundary condition. The interaction between soil and atmosphere, a topic identified as fundamental by several researchers, is still difficult to characterize and constitutes an important issue for future works.

\section{Acknowledgements}

The work described here has been carried out in collaboration with many people, in the context of several research projects during the last 15 years. The author thanks his colleagues, Profs. P.C. Prat and A. Lloret and the $\mathrm{PhD}$ students from that period: G. Ávila, R. Rodríguez, M. Sánchez, M.R. Lakshmikantha, H.U. Levatti, A. Cuadrado and J. Cordero.

Financial support from the Spanish Ministry of Economy and Competitiveness (grant BIA2012-36498) is gratefully acknowledged. 


\section{References}

1. G. Blight, "Interactions between the atmosphere and the earth," Géotechnique, vol. 47, 4, pp. 715-767, (1997).

2. G. Blight, "Solar heating of the soil and evaporation from a soil surface," Géotechnique, vol. 59, no. 4, pp. 355-363, Jan. (2009).

3. Y. J. J. Cui, Y. F. F. Lu, P. Delage, and M. Riffard, "Field simulation of in situ water content and temperature changes due to ground atmospheric interactions," Géotechnique, vol. 55, no. 7, pp. 557-567, (2005).

4. Y.J. Cui, A.N. Ta, S. Hemmati, A. M. Tang, B. Gatmiri, "Experimental and numerical investigation of soil-atmosphere interaction". Engineering Geology, vol. 165 , p. $20-28$, (2013).

5. R.C. Harris. "Giant desiccation cracks in Arizona". Arizona Geology, Arizona Geological Survey, vol. 34, n. 2 (2004)

6. M.R. El Maarry, J. Kodikara, S. Wijessoriya, W. J. Markiewicz, N. Thomas. "Desiccation mechanism for formation of giant polygons on Earth and intermediatesized polygons on Mars: Results from a pre-fracture model". Earth and Planetary Sciences Letters, 323-324, p. 19-26, (2012).

7. A. Corte, A. Higashi. "Experimental research on desiccation cracks in soil". US Army Snow Ice and Permafrost Research Establishment. Research Report No 66, Corps of Engineers, Wilmette, Illinois, USA. (1960).

8. A.N. Abu-Hejleh, D. Znidarcic, "Desiccation theory for soft cohesive soils". ASCE J. of Geotechnical Engineering, vol. 121, pp 493-502, (1995).

9. J.M. Konrad, R. Ayad, "Desiccation of a sensitive clay: field experimental observations", Canadian Geotechnical Journal, vol. 34, pp 929-942. (1997).

10. R. Rodríguez, M. Sánchez, A. Ledesma, A. Lloret, "Experimental and numerical analysis of desiccation of a mining waste". Canadian Geotechnical Journal, 44, pp 644-658, (2007).

11. H. Peron, T. Hueckel, L. Laloui, L.B. Hu, "Fundamentals of desiccation cracking of fine-grained soils: experimental characterisation and mechanisms identification", Canadian Geotechnical Journal, 46, pp 1177-1201, (2009).

12. M.R. Lakshmikantha. Experimental and theoretical analysis of cracking in drying soils." PhD thesis, UPCBarcelonaTech, Spain, (2009), PhD thesis repository: http://hdl.handle.net/10803/352470

13. S. Costa, J. Kodikara, B. Shannon, "Salient factors controlling desiccation cracking of clay in laboratory experiments". Géotechnique, vol 63, pp 18-29 (2013).

14. H. Peron, J.Y. Delenne, L. Laloui, M.S. El Youssoufi, "Discrete element modelling of drying shrinkage and cracking of soils". Computers and Geotechnics, vol. 36, p. 61-69, (2009).

15. M. Sánchez, O.L. Manzoli, L.J.N. Guimaraes, "Modelling 3-D desiccation soil crack networks using a mesh fragmentation technique". Computers and Geotechnics, vol. 62, p. 27-39, (2014).
16. D. Asahina, J.E. Houseworth, J.T. Birkholzer, J. Rutquvist, J.E. Bolander, "Hydro-mechanical model for wetting/drying and fracture development in geomaterials." Computers and Geosciences, vol. 65, p. 13-23. (2014).

17. C.L. Meehan, D. Pradel, M.A. Pando, J.F. Labuz, "Stability and performance of slopes and embankments", Geo-Congress 2013. San Diego (California). ASCE, Geotechnical Special Publication No 231, (2013).

18. J. Cordero, A. Cuadrado, P. Prat, A. Ledesma, "Description of a field test involving cracking in a drying soil". E-UNSAT 2016. This Conference, (2016).

19. R.D. Holtz, W.D. Kovacs. "An Introduction to Geotechnical Engineering", Prentice Hall, Englewood Cliffs, New Jersey, (1981).

20. F.A.M. Marinho. "Shrinkage behaviour of some plastic soils". PhD thesis, University of London, London, UK (1994).

21. H. Shin, J.C. Santamarina. "Desiccation cracks in saturated fine-grained soils: Particle level phenomena and effective stress analysis. Géotechnique, vol. 51, pp. 961-972. (2011).

22. H. Peron, J.Y. Delenne, L. Laloui, M.S. El Youssoufi. "Discrete element modelling of drying shrinkage and cracking of soils". Computers and Geotechnics, vol. 36, pp. 61-69. (2009).

23. G. Ávila, A. Ledesma, A. Lloret. "One-dimensional cracking model in clayey soils". Proc. 18th Int. Conference on Soil Mechanics and Geotech. Engng., Paris (2013).

24. H.U. Levatti. "Estudio experimental y análisis numérico de la desecación en suelos arcillosos". $\mathrm{PhD}$ Thesis (in Spanish). UPC-BarcelonaTech, Spain (2015).

25. M.R. Lakshmikantha, P.C. Prat, A. Ledesma. "Experimental evidence of size effect in soil cracking". Canadian Geotechnical Journal, vol. 49, p. 264-284, (2012).

26. A.L. Amarasiri, J.K. Kodikara. "Numerical modeling of desiccation cracking using the cohesive crack method". ASCE International Journal of Geomechanics, vol. 13, n. 3, p. 213-221. (2013).

27. G. Ávila, A. Ledesma, A. Lloret. "Measurement of fracture mechanics parameters for the analysis of cracking in soils". Proc. 3rd Int. Conference on Unsaturated Soils - UNSAT 2002. Recife, Brazil. (2002). 28. A.N. Ta. "Étude de l'interaction sol-atmosphère en chambre environnementale". $\mathrm{PhD}$ Thesis (in French). École Nationale Ponts et Chaussées- Université Paris Est. (2009).

29. J. Cordero, A. Cuadrado, A. Ledesma, P. Prat. "Patterns of cracking in soils due to drying and wetting cycles". Proc. Int. Conference on Unsaturated Soils, Research and Application, UNSAT-2014. pp. 381-387. Sydney (2014).

30. M.R. Lakshmikantha, R. Reig, P.C. Prat, A. Ledesma. "Origin and mechanism of cracks seen at the bottom of a desiccating soil specimen. ASCE GeoCongress, San Diego, USA, p. 790-799. (2013). 